\title{
Proteomic-based approach for the identification of tumor markers associated with hepatocellular carcinoma
}

\author{
Philip Shalhoub, Sarah Kern, Sophie Girard and \\ Laura Beretta* \\ Department of Microbiology and Immunology and \\ Cancer Center, University of Michigan Medical \\ School, Ann Arbor, MI 48109, USA
}

There is increasing evidence for an immune response to cancer in humans, demonstrated in part by the identification of autoantibodies to tumor antigens. The identification of panels of tumor antigens that elicit a humoral response may have utility in cancer screening, diagnosis or in establishing prognosis. Several approaches are currently available for the identification of tumor antigens. We have used a proteomic-based approach for the identification of tumor antigens that induce an antibody response which we have applied to hepatocellular carcinoma, a major type of cancer worldwide. Twodimensional gel electrophoresis allows simultaneous separation of several thousand individual proteins from tumor tissue or tumor cell lines. Proteins eliciting a humoral response in HCC were identified by 2-D Western blotting using sera from patients with hepatocellular carcinoma, followed by mass spectrometry analysis and database search. The common occurrence of autoantibodies to specific proteins may have utility for HCC screening and diagnosis.

\section{Introduction}

Primary liver cancer is a prevalent tumor worldwide. The incidence of hepatocellular carcinoma (HCC), the major histological form of primary liver cancer, has substantially increased in Japan [1], Western Europe [2, 3], and the United States [4] over the past two decades. The age-specific incidence of this cancer has also shown a progressive shift towards younger people (40

* Address for correspondence: Laura Beretta, Dept. of Microbiology and Immunology, University of Michigan, 1510 MSRB-I, 1150 W. Medical Ctr. Dr., Ann Arbor, MI 48109-0666, USA. Tel.: +1 734 615 5964; Fax: +1 734615 6150; E-mail: berettal@umich.edu. to 60 years old). Human hepatocarcinogenesis is a multistage process with the involvement of a multifactorial aetiology and many gene-environment interactions. It is important to emphasize the heterogeneity of the histological background on which the tumor develops. The majority of HCCs are associated with cirrhosis (at least $90 \%$ in America and Europe). These tumors often have a poor prognosis, with five-year survival rates of less than 5\%. Some tumors will occur in livers with minimal histological changes and "benign" adenomas can even develop in normal livers. This heterogeneity likely reflects different environmental, as well as possibly genetic factors. A large number of epidemiological and molecular studies have clearly indicated the major importance of environmental factors in the development of primary liver cancers in humans. The role of genetic factors has also been raised but is difficult to properly address, due to confounding variables such as intrafamilial transmission of HBV [5].

\section{Risk factors for the development of HCC}

Some factors in the pathogenesis of HCC have been defined and almost all tumors occur in the context of chronic liver-cell injury, inflammation, and increased turnover of hepatocytes. Cirrhosis is a very important risk factor for HCC [6], with the risk increasing by a factor of approximately 200 after the onset of cirrhosis, and up to $30-50 \%$ of patients with cirrhosis developing an $\mathrm{HCC}$ upon 10 years follow up.

Chronic infection by hepatitis B (HBV) or C (HCV) virus is also a major risk factor for $\mathrm{HCC}$, and development of a chronic carrier state is a most frequent event following acute viral infection [7,8]. The global distribution of HCC correlates well with the geographic prevalence of chronic carriers of $\mathrm{HBV}$, who number 400 million worldwide. With persistent HBV infection, the risk of HCC increases by a factor of 100 [9]. 
Among those who become infected with $\mathrm{HBV}$ at birth, men have an estimated lifetime risk of $\mathrm{HCC}$ of $50 \%$, while women have a risk of $20 \%$ [10]. Persistent infection with $\mathrm{HCV}$ is also an important risk factor for $\mathrm{HCC}$ development. As is true for HBV, the relative risk of HCC among persons with chronic HCV infection is approximately 100 times the risk in uninfected persons. Persistent HCV infection is the cause of $70 \%$ of the cases of HCC in Japan [11], and the most likely reason for the rising incidence of HCC in the United States is the spread of HCV infection in the population. Four million people in the United States have chronic HCV infection and persistent $\mathrm{HCV}$ infection is the cause of approximately $30-50 \%$ of the HCC cases in the United States.

The mechanisms involved in virally related liver carcinogenesis still remain largely undefined. There is evidence for direct effects of HBV in this process; in contrast, there is presently only very preliminary information regarding the carcinogenic role of HCV. Persistent viral infection causes inflammation, increased cell turnover and cirrhosis. Furthermore, the HBV genome may be integrated into the chromosomes of hepatocytes, contributing to genomic instability. As in persistent $\mathrm{HBV}$ infection, persistent $\mathrm{HCV}$ infection also initiates inflammation, cellular injury, regeneration, and cirrhosis, all of which may contribute to the oncogenic process. Prevention of chronic infection with these viruses by immunization is a high priority, and childhood vaccination against $\mathrm{HBV}$ carries the greatest potential for reducing the liver cancer burden. Safe and effective HBV vaccines are available, both plasmaderived and recombinant DNA-derived, although they are not yet used universally because of cost. An HCV vaccine is not yet available and may be difficult to develop because of the high mutation rate of the viral genome and variability of genotypes.

Epidemiological studies have demonstrated a strong association between exposure to aflatoxin and an increased incidence of HCC [12]. Aflatoxins have been found as contaminants in food, particularly in corn, peanut oil, soya sauce and fermented soya beans. Excessive alcohol consumption and tobacco smoking may also be associated with increased risk of HCC.

\section{Prevention of $\mathrm{HCC}$}

A goal of cancer prevention is the detection of latent premalignant or malignant clones before they expand to a clinically detectable tumor. Resection of small HCC remains an important approach in achieving long-term HCC survival and to improving 5-year survival rates. It is more effective than treatment of large HCC, surgical cure being rarely possible. Therefore, it is accepted that early detection, diagnosis and treatment of HCC remains an important target to be achieved before a breakthrough appears on the primary prevention of HCC. As high risk factors for developing HCC have been established, mass health screening for early detection of HCC is available. Initial screening should be done as early as possible on patients with chronic HBV and HCV infection, cirrhosis, and persons who had blood transfusions or a family history of HCC. The screening test currently used and widely practiced for HCC includes serum alpha-fetoprotein (AFP) levels and abdominal ultrasound examinations. Annual screening with ultrasound and AFP fails to identify potentially curable tumors because the diagnosis is often only made at a late stage of the disease [13]. Therefore a follow-up every 3 to 6 months is necessary. Although the screening can identify small tumors, survival may not be improved because the presence of cirrhosis may limit the number of patients who can undergo resections. In addition, recurrences or second primary tumors are common. Screening all liver cirrhosis patients is a questionable approach because it is very expensive and its benefit in terms of patient survival is poor. Conflicting data on the utility and efficacy of screening patients with cirrhosis for early detection of $\mathrm{HCC}$ and failures in the screening of chronic hepatitis $\mathrm{B}$ or $\mathrm{C}$ virus-infected patients with ultrasound and AFP have been reported [14]. Additional targeted screening programs with definite risk factors are dramatically needed.

\section{Tumor markers}

Several tumor markers of HCC have been identified. However, no evidence has been obtained indicating that the detection of these markers precedes clinical diagnosis of HCC. Aberrant expression of the AFP gene in serum is characteristic of a majority of HCC cases and is widely used as tumor marker in the evaluation of prognosis and management of patients with HCC [15]. Long considered the fundamental marker for diagnosis of HCC, the usefulness of AFP as a marker has slowly become overshadowed by its inability to efficiently diagnose early-stage tumors. A high false-negative diagnosis rate, sometimes reaching $40 \%$ [16], is also a problem associated with this marker. A fucosylated 
subtype of AFP, termed Lens culinaris agglutinin A reactive AFP, has been shown to be significantly better in identifying early HCC than general AFP levels [17-19].

The search for new tumor markers has long been sought. Many searches are not aimed at replacing this rather valuable marker, but instead hope to couple AFP serum levels with another marker to produce a more definitive diagnosis. An example of such a marker is des-gamma-carboxy prothrombin (DCP), an abnormal prothrombin which has long been considered a reasonable indicator of HCC, particularly when used as a complementary marker with AFP [20-28]. It has been suggested that elevation of DCP levels in HCC patients are due to a vitamin $\mathrm{K}$ deficiency in the cancerous tissue [29]. DCP serum level was found to be one of the most significant indicators of recurrence of HCC in patients [30]. DCP levels have also been found to be a good indicator of portal venous invasion (PVI) in HCC patients, which heralds the progression of the disease [31]. One issue concerning DCP is the difficulty in detecting a small level in the serum, which is often a diagnostic indicator in early stage HCC patients.

New generations of sensitive immunoassays for detection of minute serum DCP levels have recently been reported to be effective in patients with small-sized HCC [26,27,32].

The diagnostic value of serum gamma-glutamyl transferase (GGT) has also been under evaluation [33], particularly that of an isoenzyme specific to HCC. Recently, hepatoma-specific bands of this enzyme (HSGGT) were identified and found to be significantly increased in patients with HCC as compared to acute hepatitis, chronic hepatitis, cirrhosis, and extrahepatic tumors, and thus were found to be a useful tumor marker for AFP-negative HCC patients. Its use in combination with AFP serum levels has been proposed for monitoring chronic liver disease patients and diagnosing HCC [16]. The methylation status of the GGT gene has also been given consideration as hypomethylation of the CCGG sites of the GGT gene has been implicated in the abnormal expression of GGT in HCC patients [16].

Platelet-derived endothelial cell growth factor (PDECGF) has been demonstrated to be highly expressed in advanced stage $\mathrm{HCC}$ patients and has been suggested to induce rich neovascularization of tissue in HCC [34]. Although there is little usefulness for PD-ECGF measurement as an early diagnostic marker for $\mathrm{HCC}$, its value lies in the prospect of using PD-ECGF as a prognostic marker of tumor development in advanced stage patients. Plasma vascular endothelial growth factor (VEGF) levels were also shown to be significantly in- creased in patients with HCC. More specifically, the largest increase was seen after the disease has metastasized, which suggests some utility as a cancer stage specific marker [35]. It has been found to be a useful marker in detecting metastasis of $\mathrm{HCC}$, and may have valuable prognostic value in patient care. A recent study has confirmed both VEGF and PD-ECGF as useful markers for identifying $\mathrm{HCC}$, and has also reported a strong correlation between portal vein tumor thrombus (PVTT) development in HCC patients and serum levels of these markers [36].

A few additional tumor markers have been proposed, such as: plasma nitrate/nitrite [37,38], MXR7 [39] fibroblast growth factor [40], the CD24 gene [41], alpha-L-fucosidase [42], serum C-reactive protein [43], and activin-A [44]. Further research will determine whether or not these markers will prove valuable in diagnosing HCC.

\section{Identification of new HCC tumor-associated antigens using proteomics}

The common occurrence of autoantibody formation to certain cancer-related proteins may also have value in cancer screening and diagnosis. For example, mutations in the p53 tumor suppressor gene are present in up to $37 \%$ of patients with HCC. Conformational change and cellular accumulation can initiate an immune response with generation of circulating autoantibodies to $\mathrm{p} 53$ protein. However, the presence of p53 autoantibodies in patients with chronic liver disease is not completely specific for HCC and no direct evidence has been obtained that indicates p53 autoantibody formation precedes the clinical diagnosis of HCC $[45,46]$. Antigens that have been shown to induce a humoral response in HCC include diverse other nuclear proteins [47-51], cyclin B1 [52] and a novel cytoplasmic protein with RNA-binding motifs [53].

Methods have been developed to identify tumor associated antigens such as molecular cloning in expression systems [54,55] or using a biochemical strategy, based on the extraction of antigenic peptides bound to major histocompatibility complex class I molecules from tumor cells [56,57]. These methods have allowed the recognition of several human tumor antigens [58-62]. A method called SEREX, 'serological identification of antigens by recombinant expression cloning', has been recently used for the identification of tumor antigens [63]. The SEREX analysis is based on screening of autoantibodies in sera from cancer patients against an 

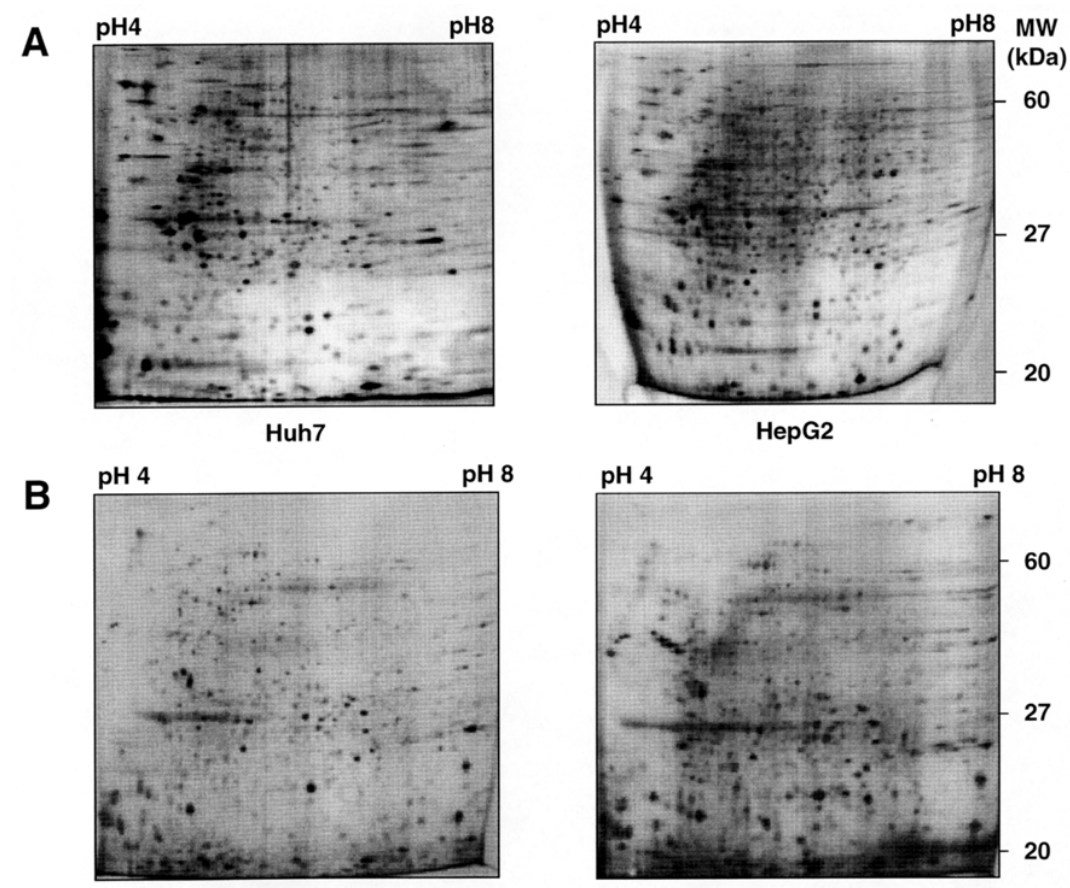

HCC1

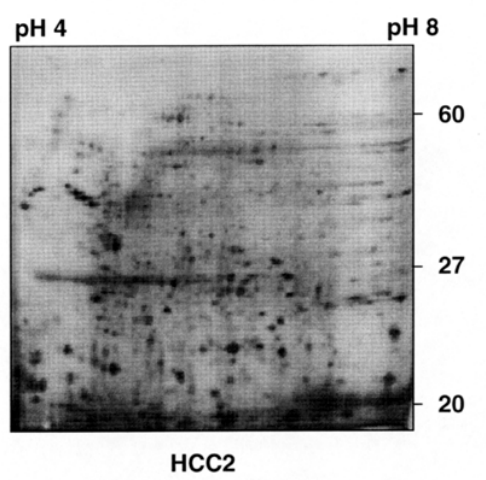

Fig. 1. 2-D PAGE protein profile of hepatoma cell lines and tumor tissues. Total proteins from the hepatoma cell lines Huh7 and HepG2 (A) and from tumor tissues obtained from 2 patients with HCC (B) were separated by 2-D electrophoresis and subsequently silver-stained.

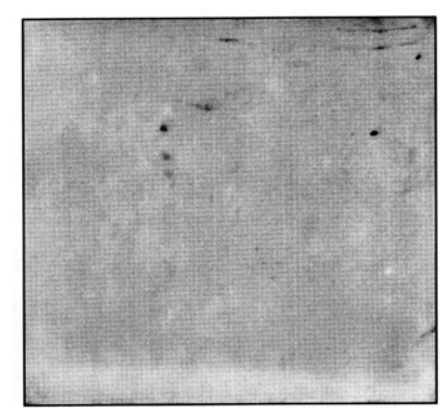

Healthy individual

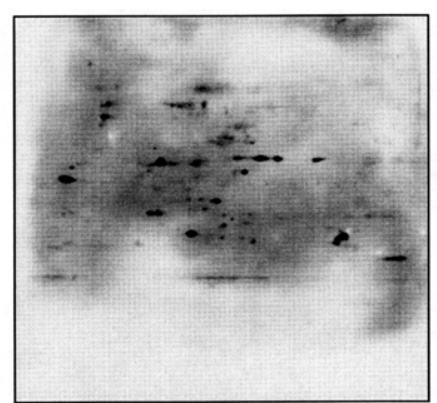

Patient with HCC

Fig. 2. Detection of autoantibodies in sera from patients with HCC. The proteins from the hepatoma cell line Huh7 were separated by 2-D electrophoresis and subsequently transferred on PVDF membranes for Western-blotting experiments using sera from a healthy individual (left panel) or from a patient with HCC (right panel) as a first antibody.

expression library made with the RNA from the autologous tumor. Through application of this strategy, an unexpected frequency of tumor antigens that elicit specific immune responses in the autologous host has been observed [63-66]. The SEREX approach is limited by the necessity to construct expression libraries and the analysis is usually restricted to one or a few patients. In addition, the approach does not allow the identification of antibodies directed against post-translational modifications. A SEREX study of hepatocellular carcinoma has uncovered reactivity to diverse proteins involved in the transcription/translational machinery as well as to chaperone proteins [67].

In order to identify proteins eliciting humoral responses in HCC patients, we used a proteome-based approach that has been recently implemented in other studies [68-70]. Several thousand cellular proteins from hepatoma cell lines or from liver tumor tissues, were separated by 2-D PAGE. Figure 1 shows the protein profile of 2 commonly used hepatoma cell lines, 
Huh7 and HepG2 (Fig. 1(A)) and of tumor tissues isolated from 2 patients with HCC (Fig. 1(B)). Proteins from hepatoma cell lines or from liver tumor tissues were then transferred onto membranes. Sera from HCC cancer patients were screened individually for antibodies that react against separated proteins. The autoantigens were detected using a secondary antibody directed against human IgM or IgG, followed by autoradiography. As shown in Fig. 2, a greater number of reactive proteins were detected in general with sera from patients with HCC than with sera from healthy individuals. Proteins that specifically reacted with sera from HCC patients were located on silver-stained 2-D gels after superimposition with the blots, extracted from the gel, digested and identified by mass spectrometric analysis and/or amino acid sequencing. We identified 8 proteins for which autoantibodies were detected in sera of more than $10 \%$ of 37 patients with HCC tested, but not in sera from healthy individuals (manuscript submitted). Autoantibodies against four of these proteins (beta-tubulin, hsp60, cytokeratin 18 and creatine kinase-B) were detected at a comparable frequency in sera from patients with chronic hepatitis. The other four proteins, which consisted of calreticulin isoforms, cytokeratin 8, nucleoside diphosphate kinase A and F1-ATP synthase beta subunit all induced autoantibodies among patients with HCC independently of their HBV/HCV status. The protein F1-ATP synthase beta subunit was previously reported to be antigenic in patients with HCC, by SEREX [67]. Calreticulin and a protein spot with an estimated MW of $32 \mathrm{kDa}$ most frequently elicited autoantibodies among patients with HCC (27\%). We previously identified this $32 \mathrm{kD}$ protein as a new truncated form of calreticulin corresponding to the $\mathrm{C}$-terminal end of the protein, and designated this novel form Crt32 [71]. The protein calreticulin has been identified as an autoantigen in various rheumatic diseases [72]. However, whereas the epitopes eliciting a humoral response in patients with autoimmune diseases have been reported to be located in the N-terminal part of the molecule, the epitopes eliciting a humoral response in patients with HCC in our study, are located in the C-terminal portion. In addition, autoantibodies against Crt32 were largely restricted to liver cancer patients among the different cancer sera we have analyzed.

\section{Conclusion}

A proteome-based approach allows individual screening of a large number of patient sera as well as detection of autoantibodies directed against post-translational modifications of specific targets. We observed a distinct repertoire of autoantibodies associated with HCC, reflecting the heterogeneity of the tumor. These autoantibodies may have utility in early diagnosis of HCC among high-risk subjects with chronic hepatitis and/or cirrhosis and may be used in combination assay with serum AFP or other marker levels. This global analysis also emphasizes the need for specific markers used in targeted screening programs with defined risk factors.

\section{References}

[1] K. Okuda, I. Fujimoto, A. Hanai AND Y. Urano, Changing incidence of hepatocellular carcinoma in Japan, Cancer Res 47 (1987), 4867-4972.

[2] S.D. Taylor Robinson, G.R. Foster, S. Arora, S. Hargreaves and H.C. Thomas, Increase in primary liver cancer in the UK, 1979-94, Lancet 350 (1997), 1142-1143.

[3] S. Deuflic, T. Poynard, L. Buffat and A.J. Valleron, Trends in primary liver cancer, Lancet 351 (1998), 214-215.

[4] H.B. El-Serag and A.D. Mason, Rising incidence of hepatocellular carcinoma in the United States, $N$ Engl J Med 340 (1999), 745-750.

[5] N.R. Drinkwater and G.H. Lee, Genetic susceptibility to liver cancer, Liver Regeneration and Carcinogenesis (1995), 301314.

[6] K. Ikeda, S. Saitoh and Koida et al., A multivariate analysis of risk factors for hepatocellular carci, ogenesis: A prospective observation of 795 patients with viral and alcoholic cirrhosis, Hepatology 18 (1993), 47-53.

[7] C. Brechot, F. Jaffredo and D. Lagorce et al., Impact of HBV, $\mathrm{HCV}$ and $\mathrm{GBV}-\mathrm{C} / \mathrm{HGV}$ on hepatocellular carcinomas in Europe: results of a european concerted action, J Hepatol 29 (1998), 173-183.

[8] K. Ikeda, S. Saitoh and Y. Suzuki et al., Disease progression and hepatocellular carcinogenesis in patients with chronic viral hepatitis: a prospective observation of 2215 patients, $J$ Hepatol 28 (1998), 930-938.

[9] R.P. Beasley, L.Y. Hwang, C.C. DLin and C.S. Chien, Hepatocellular carcinoma and hepatitis B virus: a prospective study of 22707 men in Taiwan, Lancet 2 (1981), 1129-1133.

[10] D. Moradpour and J.R. Wands, Hepatic oncogenesis, in: Hepatology: a textbook of liver disease, (Vol. 2), (3rd ed.), D. Zakim and T.D. Boyer, eds, W.B. Saunders, Philadelphia, 1996, pp. $1490-1512$.

[11] T. Heintges and J.R. Wands, Hepatitis C virus: epidemiology and transmission, Hepatology 26 (1997), 521-526.

[12] C.J. Chen, L.Y. Wang and S.N. Lu et al., Elevated aflatoxin exposure and increased risk of hepatocellular carcinoma, Hepatology 24 (1996), 38-42.

[13] F. Tradati, M. Colombo and P.M. Mannucci et al., A prospective multicenter study of hepatocellular carcinoma in italian hemophiliacs with chronic hepatitis $\mathrm{C}$. The study group of the association of italian hemophilia centers, Blood 91 (1998), 1173-1177.

[14] F. Izzo, F. Cremona, F. Ruffolo, R. Palaia, V. Parisi and S.A. Curley, Outcome of 67 patients with hepatocellular cancer detected during screening of 1125 patients with chronic hepatitis, Ann Surg 227 (1998), 513-518. 
[15] S. Ho and P.J. Johnson, Detection of alphafetoproteinexpressing cells in the blood of patients with hepatoma and hepatitis, Br J Cancer 77 (1998), 2059.

[16] D. Yao, D. Jiang and Z. Huang et al., Abnormal expression of hepatoma specific gamma-glutamyl transferase and alteration of gamma-glutamyl transferase gene methylation status in patients with hepatocellular carcinoma, Cancer 88(4) (15 Feb. 2000), 761-769.

[17] K. Taketa, Y. Endo and C. Sekiya et al., A collaborative study for the evaluation of lectin-reactive $\alpha$-fetoproteins in early detection of hepatocellular carcinoma, Cancer Res 53 (1993), 5419-5423.

[18] Y. Aoyagi, Carbohydrate-based measurements on alphafetoprotein in the early diagnosis of hepatocellular carcinoma Glycoconj J 12(3) (June 1995), 194-199.

[19] F. Yamashita, M. Tanaka, S. Satomura and K. Tanikawa, Prognostic significance of Lens culinaris agglutinin A-reactive alpha-fetoprotein in small hepatocellular carcinomas, Gastroenterology 111(4) (Oct 1996), 996-1001.

[20] H.A. Liebman, B.C. Furie and M. Tong et al., Des- $\gamma$-carboxy (abnormal) prothrombin as a serum marker of primary hepatocellular carcinoma, N Engl J Med 310 (1984), 1427-1431.

[21] S. Fujiyama, T. Morishita, K. Sagara, T. Sato, K. Motohara and I. Matsuda, Clinical evaluation of plasma abnormal prothrombin (PIVKA-II) in patients with hepatocellular carcinoma, Hepatogastroenterology 33(5) (Oct 1986), 201-205.

[22] C.H. Ho, S.D. Lee, H.T. Chang, J.C. Wu, Y.T. Tsai and K.J. Lo, Application of des-gamma-carboxy prothrombin as a complementary tumor marker with alpha-fetoprotein in the diagnosis of hepatocellular carcinoma, Scand J Gastroenterol 24(1) (Jan 1989), 47-52.

[23] A. Nakao, A. Virji, Y. Iwaki, B. Carr, S. Iwatsuki and E. Starzl, Abnormal prothrombin (DES-gamma-carboxy prothrombin) in hepatocellular carcinoma, Hepatogastroenterology 38(5) (Oct 1991), 450-453.

[24] I.C. Weitz and H.A. Liebman, Des-gamma-carboxy (abnormal) prothrombin and hepatocellular carcinoma: a critical review, Hepatology 18(4) (Oct 1993), 990-997.

[25] G.L. Grazi, A. Mazziotti and C. Legnani et al., The role of tumor markers in the diagnosis of hepatocellular carcinoma, with special reference to the des-gamma-carboxy prothrombin, Liver Transpl Surg 1(4) (July 1995), 249-255.

[26] H. Okuda, T. Nakanishi and K. Takatsu et al., Measurement of serum levels of des-gamma-carboxy prothrombin in patients with hepatocellular carcinoma by a revised enzyme immunoassay kit with increased sensitivity, Cancer 85(4) (15 Feb 1999), 812-818.

[27] K. Soga, T. Watanabe, K. Aikawa, M. Toshima, K. Shibasaki and Y. Aoyagi, Serum des-gamma-carboxyprothrombin level by a modified enzyme immunoassay method in hepatocellular carcinoma: clinical significance in small hepatocellular carcinoma, Hepatogastroenterology 45(23) (Sep-Oct 1998), 1737-1741.

[28] T. Sassa, T. Kumada, S. Nakano and T. Uematsu, Clinical utility of simultaneous measurement of serum high-sensitivity des-gamma-carboxy prothrombin and Lens culinaris agglutinin A-reactive alpha-fetoprotein in patients with small hepatocellular carcinoma, Eur J Gastroenterol Hepatol 11(12) (Dec 1999), 1387-1392.

[29] T. Miyakawa, Y. Kajiwara, A. Shirahata, K. Okamoto, H Itoh and K. Ohsato, Vitamin K contents in liver tissue of hepatocellular carcinoma patients, Jpn J Cancer Res 91(1) (Jan 2000), 68-74.
[30] M. Shimada, Y. Yamashita and T. Hamatsu et al., The role of des-gamma-carboxy prothrombin levels in hepatocellular carcinoma and liver tissues, Cancer Lett 159(1) (16 Oct 2000), 87-94.

[31] Y. Koike, Y. Shiratori and S. Sato et al., Des- $\gamma$-Carboxy Prothrombin as a useful predisposing factor for the development of portal venous invasion in patients with hepatocellular carcinoma: a prospective analysis of 227 patients, Cancer 91(3) (1 Feb 2001), 561-569.

[32] F. Nomura, M. Ishijima, K. Kuwa, N. Tanaka, T. Nakai and K. Ohnishi, Serum des-gamma-carboxy prothrombin levels determined by a new generation of sensitive immunoassays in patients with small-sized hepatocellular carcinoma, Am J Gastroenterol 94(3) (March 1999), 650-654.

[33] K. Xu, X.Y. Meng, J.W. Wu, B. Shen, Y.C. Shi and Q. Wei, Diagnostic value of serum gamma-glutamyl transferase isoenzyme for hepatocellular carcinoma: a 10-year study, Am J Gastroenterol 87(8) (Aug 1992), 991-995.

[34] K. Jin-no, M. Tanimizu and I. Hyodo et al., Circulating platelet-derived endothelial cell growth factor increases in hepatocellular carcinoma patients, Cancer 82(7) (1 April 1998), 1260-1267.

[35] K. Jin-no, M. Tanimizu and I. Hyodo et al., Circulating vascular endothelial growth factor (VEGF) is a possible tumor marker for metastasis in human hepatocellular carcinoma, $J$ Gastroenterol 33(3) (June 1998), 376-382.

[36] J. Zhou, Z.Y. Tang and J. Fan et al., Expression of plateletderived endothelial cell growth factor and vascular endothelial growth factor in hepatocellular carcinoma and portal vein tumor thrombus, J Cancer Res Clin Oncol 126(1) (Jan 2000), $57-61$.

[37] A. Moriyama, A. Masumoto and H. Nanri et al., High plasma concentrations of nitrite/nitrate in patients with hepatocellular carcinoma, Am J Gastroenterol 92(9) (Sep 1997), 1520-1523.

38] A. Moriyama, A. Tabaru, H. Unoki, S. Abe, A. Masumoto and M. Otsuki, Plasma nitrite/nitrate concentrations as a tumor marker for hepatocellular carcinoma, Clin Chim Acta 296(12) (June 2000), 181-191.

[39] H.C. Hsu, W. Cheng and P.L. Lai, Cloning and expression of a developmentally regulated transcript MXR7 in hepatocellular carcinoma: biological significance and temporospatial distribution, Cancer Res 57(22) (15 Nov 1997), 5179-5184.

[40] P.I. Hsu, N.H. Chow and K.H. Lai et al., Implications of serum basic fibroblast growth factor levels in chronic liver diseases and hepatocellular carcinoma, Anticancer Res 17(4A) (JulAug 1997), 2803-2809.

[41] L.R.Huang and H.C. Hsu, Cloning and expression of CD24 gene in human hepatocellular carcinoma: a potential early tumor marker gene correlates with p53 mutation and tumor differentiation, Cancer Res 55(20) (15 Oct 1995), 4717-4721.

[42] P. Tangkijvanich, P. Tosukhowong and P. Bunyongyod et al., Alpha-L-fucosidase as a serum marker of hepatocellular carcinoma in Thailand, Southeast Asian J Trop Med Public Health 30(1) (March 1999), 110-114.

[43] Z.Y. Lin, L.Y. Wang and M.L. Yu et al., Role of serum Creactive protein as a marker of hepatocellular carcinoma in patients with cirrhosis, J Gastroenterol Hepatol 15(4) (Apr 2000), 417-421.

[44] M. Pirisi, C. Fabris and S. Luisi et al., Evaluation of circulating activin-A as a serum marker of hepatocellular carcinoma, Cancer Detect Prev 24(2) (2000), 150-155.

[45] J. Raedle, G. Oremek and M. Truschnowitsch et al., Clinical evaluation of autoantibodies to p53 protein in patients with 
chronic liver disease and hepatocellular carcinoma, Eur. J. Cancer 34 (1998), 1198-1203.

[46] R. Saffroy, J.C. Lelong and D. Azoulay et al., Clinical significance of circulating anti-p53 antibodies in European patients with hepatocellular carcinoma, Br J Cancer 79 (1999), 604-610.

[47] H. Imai, E.K. Chan, K. Kiyosawa, X.D. Fu and E.M. Tan, Novel nuclear autoantigen with splicing factor motifs identified with antibody from hepatocellular carcinoma, J Clin Invest 92 (1993), 2419-2426.

[48] Y. Muro, E.K. Chan, G. Landberg and E.M. Tan, A cellcycle nuclear autoantigen containing WD-40 motifs expressed mainly in S and G2 phase cells, Biochem Biophys Res Commun 207 (1995), 1029-1037.

[49] H. Imai, R.L. Ochs, K. Kiyosawa, S. Furuta, R.M. Nakamura and E.M. Tan, Nucleolar antigens and autoantibodies in hepatocellular carcinoma and other malignancies, Am J Pathol 140 (1992), 859-870

[50] G. Covini, C.A. von Muhlen, S. Pacchetti, M. Colombo, E.K Chan and E.M. Tan, Diversity of antinuclear antibody responses in hepatocellular carcinoma, J Hepatol 26 (1997), 1255-1265.

[51] H. Imai, K. Furuta, G. Landberg, K. Kiyosawa, L.F. Liu and E.M. Tan, Autoantibody to DNA topoisomerase II in primary liver cancer, Clin Cancer Res 1 (1995), 417-424.

[52] G. Covini, E.K. Chan, M. Nishioka, S.A. Morshed, S.I. Reed and E.M. Tan, Immune response to cyclin B1 in hepatocellular carcinoma, Hepatology 25 (1997), 75-80.

[53] J.Y. Zhang, E.K. Chan, X.X. Peng and E.M. Tan, A novel cytoplasmic protein with RNA-binding motifs is an autoantigen in human hepatocellular carcinoma, J Exp Med 189 (1999), 1101-1110.

[54] E. De plaen, C. Lurquin and A. van Pel et al., Immunogenic (tum-) variants of mouse tumor P815: cloning of the gene of tum- antigen P91A and identification of the tum- mutation, Proc Natl Acad Sci USA 85 (1988), 2274-2278.

[55] P. Van der Bruggen, C. Traversari and P. Chomez et al., A gene encoding an antigen recognized by cytolytic $\mathrm{T}$ lymphocytes on a human melanoma, Science 254 (1991), 1643-1647.

[56] O. Mandelboim, G. Berke, M. Fridkin, M. Feldman, M. Eisenstein and L. Eisenbach, CTL induction by a tumour-associated antigen octapeptide derived from a murine lung carcinoma, Nature 369 (1994), 67-71.

[57] A. Cox, J. Skipper and Y. Chen et al., Identification of a peptide recognized by five melanoma-specific human cytotoxic $\mathrm{T}$ cell lines, Science 264 (1994), 716-719.

[58] T. Boon and P. Van Der Bruggen, Human tumor antigens recognized by T lymphocytes, J Exp Med 183 (1996), 725729.

[59] P.F. Robbins and Y. Kawakami, Human tumor antigens recognized by T cells, Curr Opin Immunol 8 (1996), 628-636.

[60] Y. Kawakami and S.A. Rosenberg, Human tumor antigens recognized by T-cells, Immunol Res 16 (1997), 313-339.

[61] S.A. Rosenberg, Cancer vaccines based on the identification of genes encoding cancer regression antigens, Immunology Today 18 (1997), 175-182.

[62] S.A. Rosenberg, A new era for cancer immunotherapy based on the genes that encode cancer antigens, Immunity 10 (1999), 281-287.

[63] U. Sahin, O. Türeci and H. Schmitt et al., Human neoplasms elicit multiple specific immune responses in the autologous host, Proc Natl Acad Sci USA 92 (1995), 11810-11813.

[64] L.J. Old and Y.T. Chen, New paths in human cancer serology, J Exp Med 187 (1998), 1163-1167.

[65] O. Türeci, U. Sahin, C. Zwick, F. Neumann and M. Pfreundschuh, Exploitation of the antibody repertoire of cancer patients for the identification of human tumor antigens, $\mathrm{Hy}$ bridoma 18 (1999), 23-28.

[66] Y.T. Chen, Cancer vaccine: identification of human tumor antigens by SEREX, Cancer J Sci Am 6 (2000), S208-217.

[67] F. Stenner-Liewen, G. Luo and U. Sahin et al., Definition of tumor-associated antigens in hepatocellular carcinoma, Cancer Epidemiol Biomarkers Prev 9 (2000), 285-290.

[68] L. Prasannan, D.E. Misek, R. Hinderer, J. Michon, J.D. Geiger and S.M. Hanash, Identification of beta-tubulin isoforms as tumor antigens in neuroblastoma, Clin Cancer Res 6 (2000), 3949-3956.

[69] F. Brichory, D.E. Misek and A.M. Yim et al., An immune response manifested by common occurence of annexins I and II autoantibodies and high circulating levels of interleukin 6 in lung cancer, Proc Natl Acad Sci USA, in press.

[70] F. Brichory, D. Beer, F. Le Naour, T.J. Giordano and S.M. Hanash, Proteomics-based identification of PGP 9.5 as a tumor antigen that induces a humoral immune response in lung cancer, Cancer Research, in press.

[71] F. Le Naour, L. Hohenkirk and A. Grolleau et al., Profiling changes in gene expression during differentiation and maturation of monocytes-derived Dendritic cells using both oligonucleotide microarrays and proteomics, J Biol Chem 276 (2001), 17920-17931.

[72] P. Eggleton, F.J. Ward and S. Johnson et al., Fine specificity of autoantibodies to calreticulin: epitope mapping and characterization, Clin Exp Immunol 120 (2000), 384-391. 


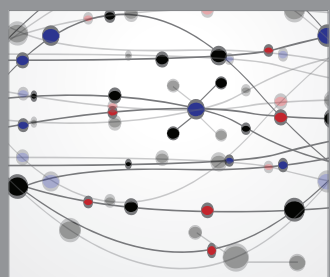

The Scientific World Journal
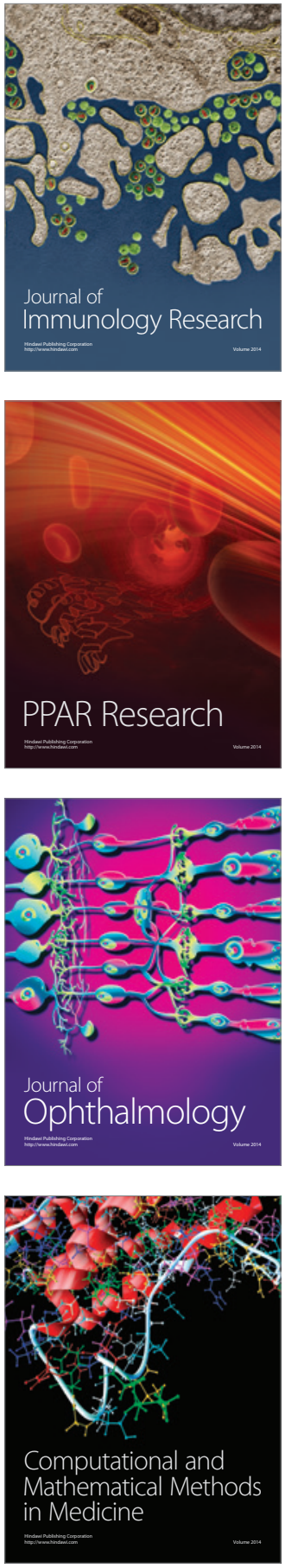

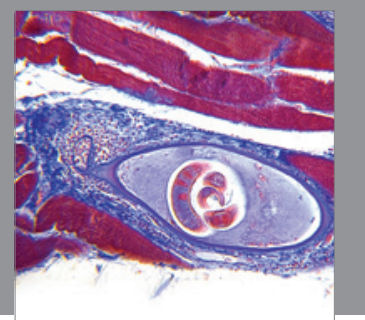

Gastroenterology

Research and Practice
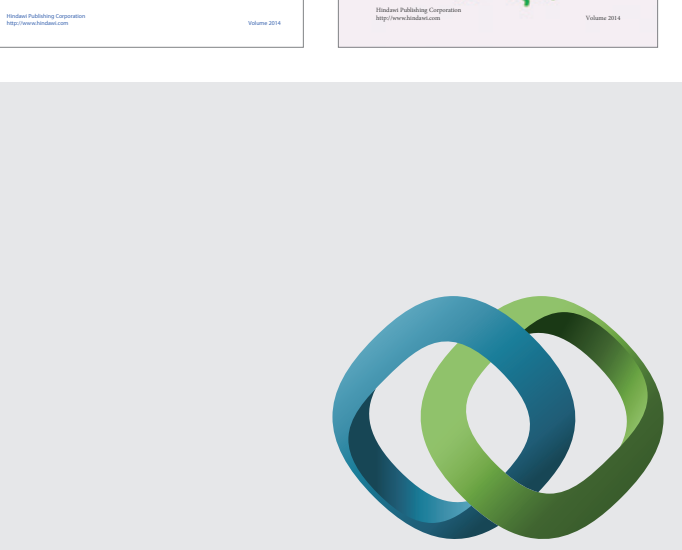

\section{Hindawi}

Submit your manuscripts at

http://www.hindawi.com
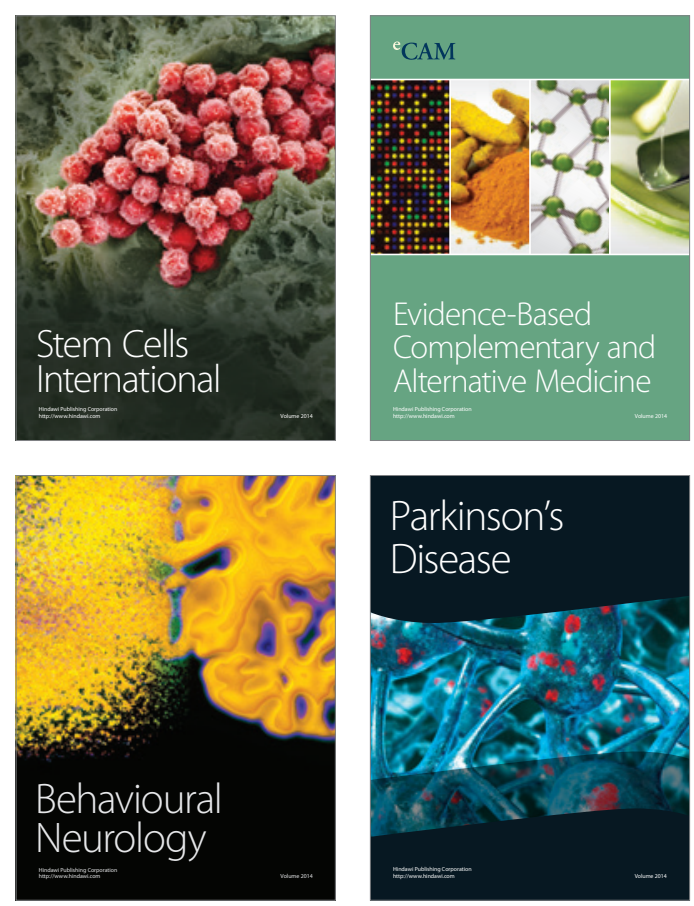

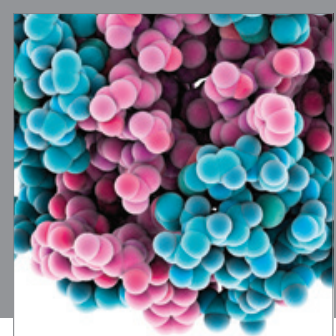

Journal of
Diabetes Research

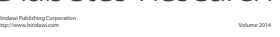

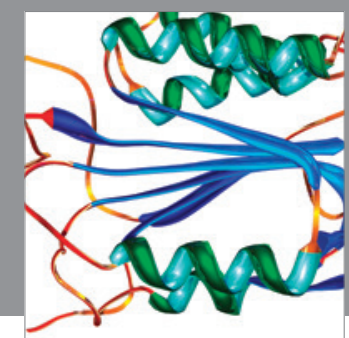

Disease Markers
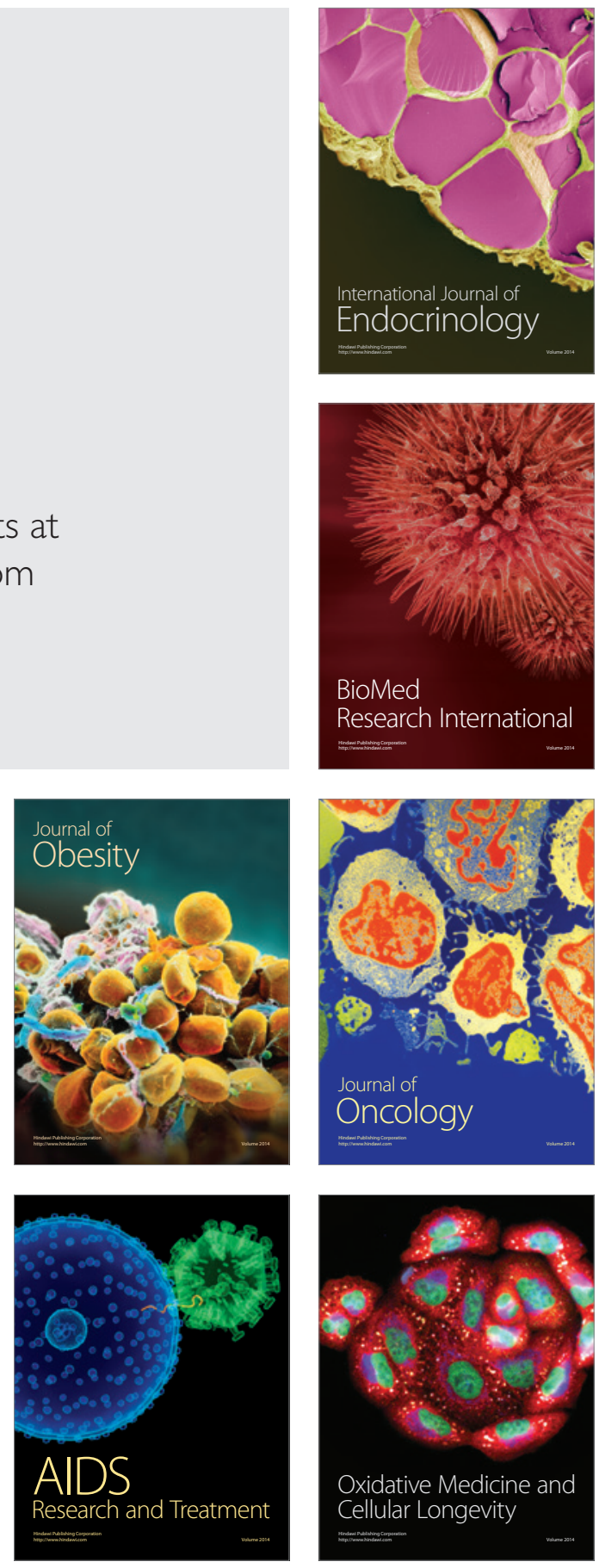